\title{
Effects of EDTA and Boric Acid on the Morphology of $\mathrm{CaCO}_{3}$ Particles
}

\author{
Xingbo Shi, ${ }^{1}$ Julin Wang, ${ }^{1}$ and Xiaoping Cai ${ }^{1,2}$ \\ ${ }^{1}$ National Carbon Fiber Engineering Research Center, Beijing University of Chemical Technology, Beijing 100029, China \\ ${ }^{2}$ Jilin Petrochemical Co. Ltd., PetroChina, Jilin 132021, China
}

Correspondence should be addressed to Julin Wang, julinwang@126.com

Received 31 July 2012; Accepted 30 November 2012

Academic Editor: Sung Oh Cho

Copyright () 2012 Xingbo Shi et al. This is an open access article distributed under the Creative Commons Attribution License, which permits unrestricted use, distribution, and reproduction in any medium, provided the original work is properly cited.

\begin{abstract}
Calcium carbonate $\left(\mathrm{CaCO}_{3}\right)$ particles with different morphologies were prepared using calcium chloride $\left(\mathrm{CaCl}_{2}\right)$ and sodium carbonate $\left(\mathrm{Na}_{2} \mathrm{CO}_{3}\right)$ aqueous solutions containing various amounts of ethylenediamine tetraacetic acid (EDTA) or boric acid. The products were characterized by X-ray diffraction (XRD) and scanning electron microscopy (SEM). The sphere-like CaCO $\mathrm{C}_{3}$ particle was inclined to be formed in EDTA or boric acid solution at room temperature. The surface of $\mathrm{CaCO}_{3}$ is smooth in the presence of EDTA, and the crystal structure of $\mathrm{CaCO}_{3}$ is majorly vaterite. However, the $\mathrm{CaCO}_{3}$ has a rough surface in boric acid solution and pure calcite structure. The size of $\mathrm{CaCO}_{3}$ particle decreases with the increase in the amount of EDTA or boric acid.
\end{abstract}

\section{Introduction}

Calcium carbonate $\left(\mathrm{CaCO}_{3}\right)$ is one of the most abundant materials on the planet and has been often used in ground form to produce polymer composites $[1,2]$. Recently, there have been some interests in controlling the crystallization of $\mathrm{CaCO}_{3}$ and the usage of various types of inorganic/organic additives in order to obtain unusual morphologies, crystal sizes, and control the outcoming polymorph type $[3,4]$. Research on the controlling mineralization of $\mathrm{CaCO}_{3}$ has focused on the following two approaches: (i) organic additives controlling the morphology and crystal structure of $\mathrm{CaCO}_{3}$. These water-soluble additives include hydrophilic synthetic polymers $[5,6]$ and low-molecular mass organic additives [7-9], such as carboxylic or amino acids. The second approach is (ii) inorganic ions controlling the morphology and crystal structure of $\mathrm{CaCO}_{3}$. It has been reported that crystallization of $\mathrm{CaCO}_{3}$ is also affected by inorganic ions, such as $\mathrm{Ba}^{2+}$ and $\mathrm{Co}^{2+}[10-12]$.

In this work, $\mathrm{CaCO}_{3}$ crystals were precipitated using aqueous mixtures of $\mathrm{CaCl}_{2}$ and $\mathrm{Na}_{2} \mathrm{CO}_{3}$ in the presence of EDTA or boric acid. The $\mathrm{CaCO}_{3}$ particles were characterized with XRD and SEM.

\section{Experimental}

Calcium chloride $\left(\mathrm{CaCl}_{2}\right)$, sodium carbonate $\left(\mathrm{Na}_{2} \mathrm{CO}_{3}\right)$, ethylenediamine tetraacetic acid (EDTA), and boric acid were purchased from Beijing Chemical Works. These agents were all analytical reagent degree.

Alkaline condition: an aqueous solution containing $50 \mathrm{~mL} \mathrm{Na} \mathrm{CO}_{3}(0.5 \mathrm{M})$ was stirred continuously for about $15 \mathrm{~min}$ at room temperature $\left(25^{\circ} \mathrm{C}\right)$, and then different amounts of EDTA or boric acid $(0.5 \mathrm{~g}, 1.0 \mathrm{~g}$ and $1.5 \mathrm{~g})$ were added. The mixed solution was alkaline because of the small amount of EDTA or boric acid. $50 \mathrm{~mL} \mathrm{CaCl}_{2}(0.5 \mathrm{M})$ was gradually added into the above mixed solution and kept stirring for $60 \mathrm{~min}$.

Acidic condition: the operation steps were same as above, the difference was only that $50 \mathrm{~mL} \mathrm{Na} \mathrm{CO}_{3}(0.5 \mathrm{M})$ was added into the mixed solution of $\mathrm{CaCl}_{2}$ and additives.

The precipitate was washed by deionized water and ethanol and then dried at $80^{\circ} \mathrm{C}$ for $24 \mathrm{~h}$.

$\mathrm{X}$-ray diffraction $(\mathrm{XRD}, 2500 \mathrm{VB} 2+\mathrm{PC}, \mathrm{Cu} \mathrm{K} \alpha$ radiation, Rigaku, Japan) was used to analyze the composition and crystal structure of the prepared micro- $\mathrm{CaCO}_{3}$ products. The shapes of the products were characterized by scanning electron microscopy (SEM, S-4700, Hitachi, Japan). 


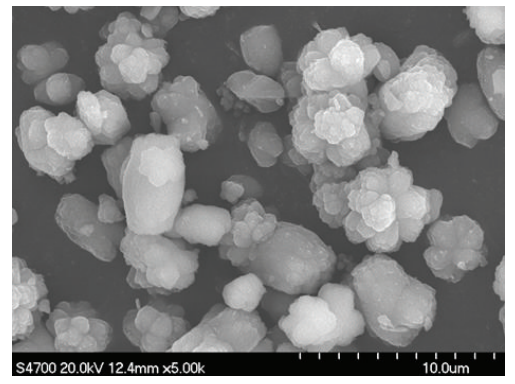

(A)

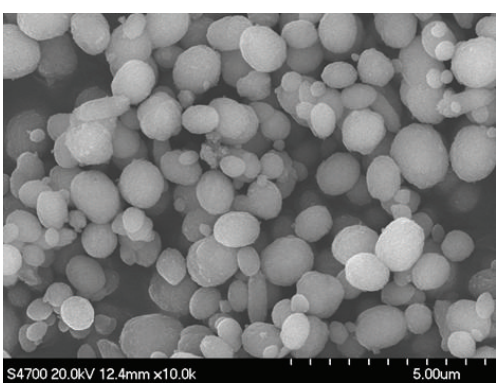

(B)

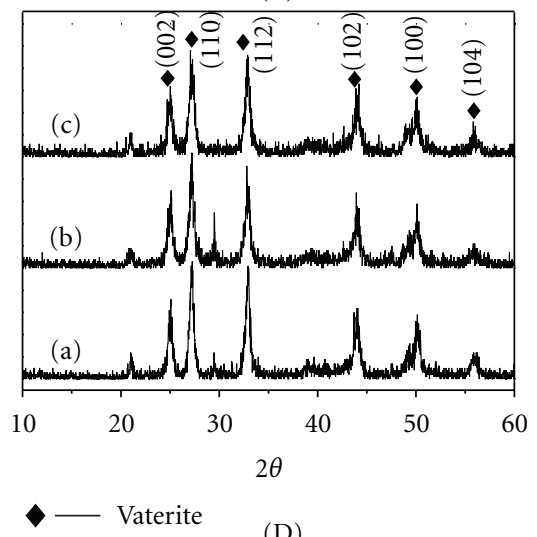

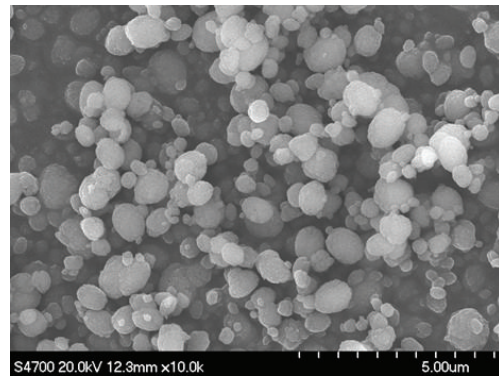

(C)

(D)

FIgURE 1: SEM images and XRD patterns of $\mathrm{CaCO}_{3}$ prepared in the presence of EDTA in alkaline condition. (A)-(C) SEM images of synthesized $\mathrm{CaCO}_{3}$, (D) XRD patterns of product $A(a)$, product $\mathrm{B}(\mathrm{b})$, and product $\mathrm{C}(\mathrm{c})$.

\section{Results and Discussion}

Figure 1 shows the SEM images and XRD patterns of the prepared $\mathrm{CaCO}_{3}$ after adding different amounts of EDTA in alkaline condition. SEM image given in Figure 1(A) indicates that the particle, produced with addition of $0.5 \mathrm{~g}$ EDTA, is a majority of flower shapes with a size of $5 \mu \mathrm{m}$. The images in Figures 1(B) and 1(C) show that the products are composed of sphere-like particles in addition of $1.0 \mathrm{~g}$ or $1.5 \mathrm{~g}$ EDTA. The nanoparticle shown in Figure $1(\mathrm{C})$ (with a diameter of $0.5 \sim 2 \mu \mathrm{m}$ ) is smaller than those shown in Figure 1(B) (with a diameter of $1 \sim 3 \mu \mathrm{m})$. From the XRD patterns of the asprepared $\mathrm{CaCO}_{3}$ (Figure $1(\mathrm{D})$ ), in comparison with their standard JCPDS files (calcite, 47-1743 and vaterite, 33-0268), the flower (Figure 1(D), (a)) and sphere-like (Figure 1(D), (b) and (c)) $\mathrm{CaCO}_{3}$ particles are major vaterite structure.

Figure 2 shows the SEM images and XRD patterns of the synthesized $\mathrm{CaCO}_{3}$ after adding different amounts of EDTA in acidic condition. Figure $2(\mathrm{~A})$ indicates that the product is composed of a rodlike particle and a small part flowerlike particle with a length of $3 \mu \mathrm{m}$ with addition of $0.5 \mathrm{~g}$ EDTA. Figure 2(D) XRD patterns of the $\mathrm{CaCO}_{3}$ demonstrate that pure calcite was produced (Figure 2(D), (a)). Figures $2(\mathrm{~B})$ and $2(\mathrm{C})$ indicate that the products compose spherelike $\mathrm{CaCO}_{3}$ particle with a diameter of $1 \sim 2.5 \mu \mathrm{m}$ in addition of $1.0 \mathrm{~g}$ or $1.5 \mathrm{~g}$ EDTA. The diffraction peaks (Figure 2(D), (b)) can be well indexed to the calcite and vaterite phase of $\mathrm{CaCO}_{3}$. The diffraction peaks from (Figure 2(D), (c)) show that the hemispherical $\mathrm{CaCO}_{3}$ is a pure vaterite structure.
Figure 3 shows the SEM images and XRD patterns of the synthesized $\mathrm{CaCO}_{3}$ in the presence of boric acid in alkaline condition. Figure 3(A) indicates that the product is a spherelike particle with a length of $2.5 \mu \mathrm{m}$ and a rough surface in the presence of $0.5 \mathrm{~g}$ boric acid. Figures $3(\mathrm{~B})$ and $3(\mathrm{C})$ indicate that the product is a cubic particle (size length of $500 \mathrm{~nm}$ or $300 \mathrm{~nm}$ ) in the presence of $1.0 \mathrm{~g}$ or $1.5 \mathrm{~g}$ boric acid. The XRD patterns of the $\mathrm{CaCO}_{3}$ can be indexed that the three kinds of products are composed of pure calcite structure (Figure 3(D)).

Figure 4 shows the SEM images and XRD patterns of the synthesized $\mathrm{CaCO}_{3}$ in the presence of boric acid in acidic condition. Figures $4(\mathrm{~A}), 4(\mathrm{~B})$, and $4(\mathrm{C})$ indicate that the products are sphere-like particle with a diameter of $2.5 \mu \mathrm{m}$, $1 \mu \mathrm{m}$, and $500 \mathrm{~nm}$ by adding $0.5 \mathrm{~g}, 1.0 \mathrm{~g}$, and $1.5 \mathrm{~g}$ boric acid, respectively. The particle surface is rough. The XRD patterns of the $\mathrm{CaCO}_{3}$ can be indexed that the three kinds of products are composed of pure calcite structure (Figure 3(D)).

Mann et al. [13] investigated the crystallization of $\mathrm{CaCO}_{3}$ from supersaturated solutions. The formation of a Stern layer of Ca counterions favors the oriented nucleation of crystal faces consisting of only $\mathrm{Ca}$ atoms and the (0001) face of vaterite fits this criterion. Charge accumulation, however, cannot account for the structural selectivity of vaterite, as the (0001) face of calcite is also uni-charged. The trigonal planar carbonate anions are oriented parallel to the (0001) face of calcite, whereas in vaterite they are aligned perpendicularly, and the latter arrangement is equivalent to the orientation of the carboxylate headgroups with respect to the Ca-bound 


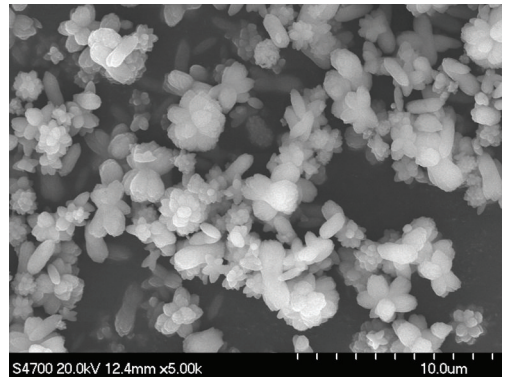

(A)

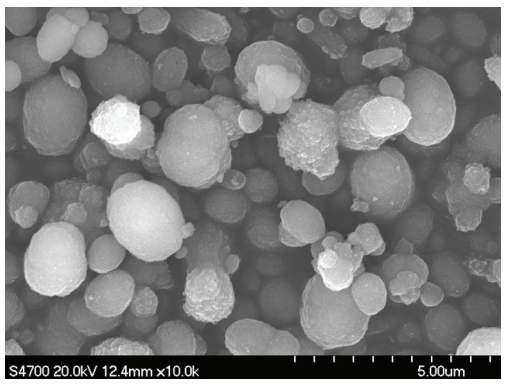

(B)

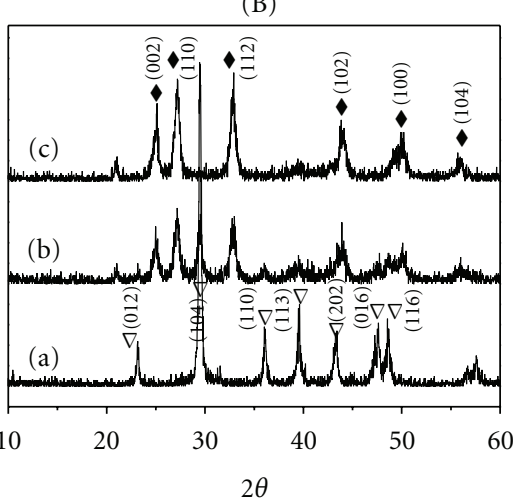

$\checkmark$ Vaterite

$\nabla-$ Calcite

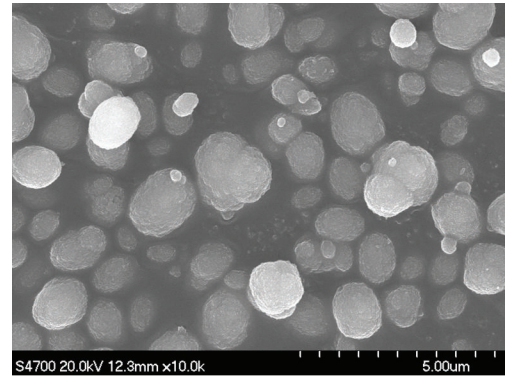

(C)

FIgure 2: SEM images and XRD patterns of $\mathrm{CaCO}_{3}$ prepared in the presence of EDTA in acidic condition. (A)-(C) SEM images of synthesized $\mathrm{CaCO}_{3}$, (D) XRD patterns of product $\mathrm{A}(\mathrm{a})$, product $\mathrm{B}(\mathrm{b})$, and product $\mathrm{C}(\mathrm{c})$.

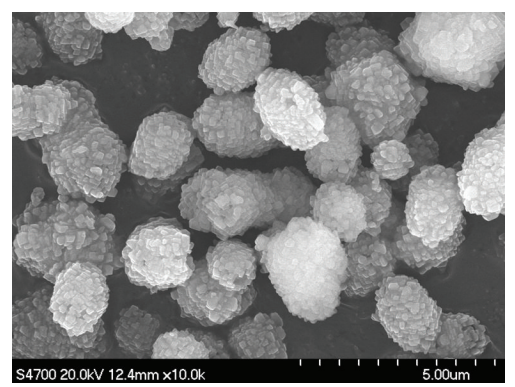

(A)

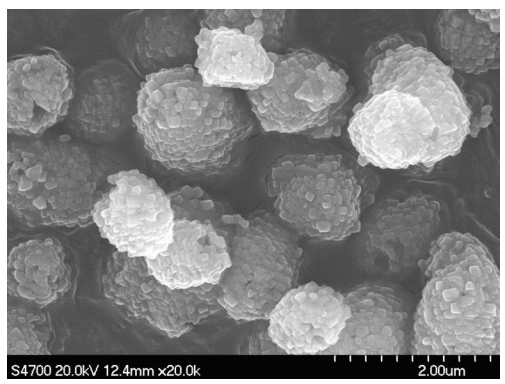

(B)

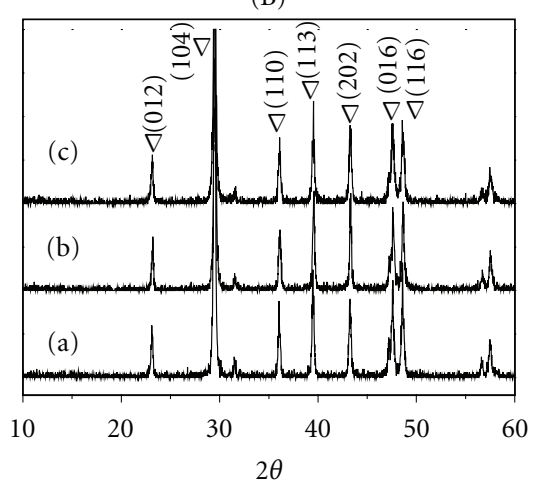

$\nabla-$ Calcite

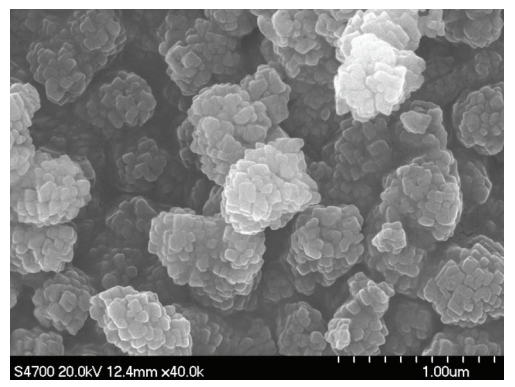

(C)

(D)

FIgURE 3: SEM images and XRD patterns of $\mathrm{CaCO}_{3}$ prepared in the presence of boric acid in alkaline condition. (A)-(C) SEM images of synthesized $\mathrm{CaCO}_{3}$, (D) XRD patterns of product $\mathrm{A}(\mathrm{a})$, product $\mathrm{B}(\mathrm{b})$, and product $\mathrm{C}(\mathrm{c})$. 


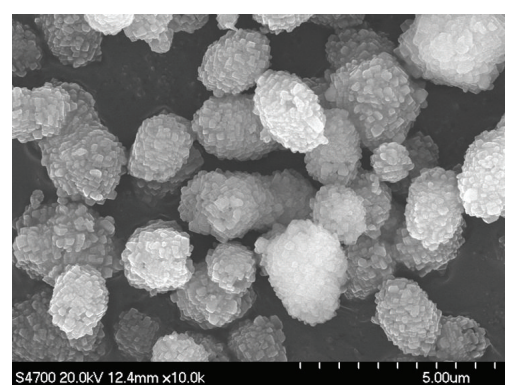

(A)

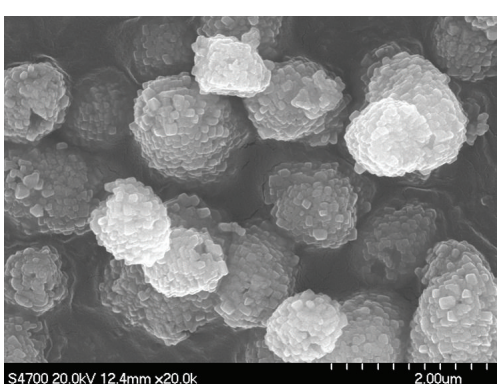

(B)

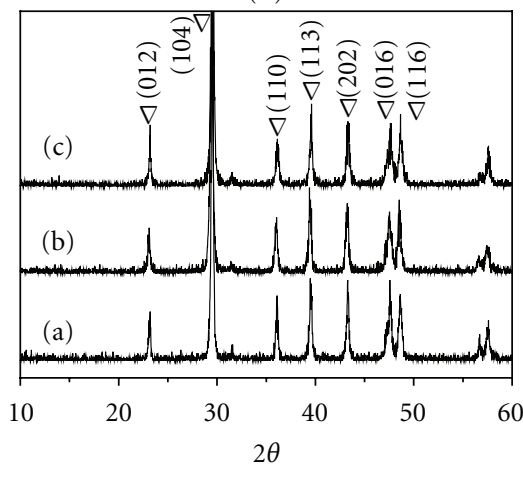

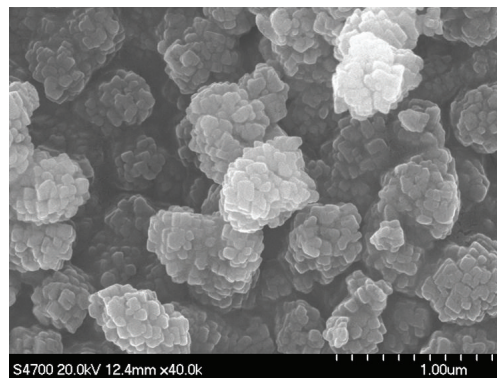

(C)

$\nabla-$ Calcite

(D)

FIgURE 4: SEM images and XRD patterns of $\mathrm{CaCO}_{3}$ prepared in the presence of boric acid in acidic condition. (A) -(C) SEM images of synthesized $\mathrm{CaCO}_{3}$, (D) XRD patterns of product $\mathrm{A}(\mathrm{a})$, product $\mathrm{B}(\mathrm{b})$, and product $\mathrm{C}(\mathrm{c})$.

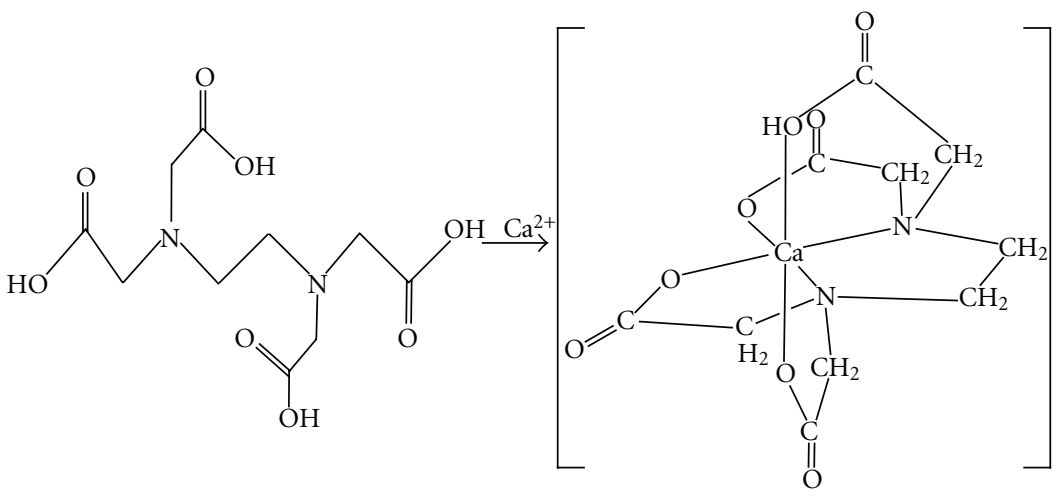

Figure 5: The chelation of EDTA and $\mathrm{Ca}^{2+}$.

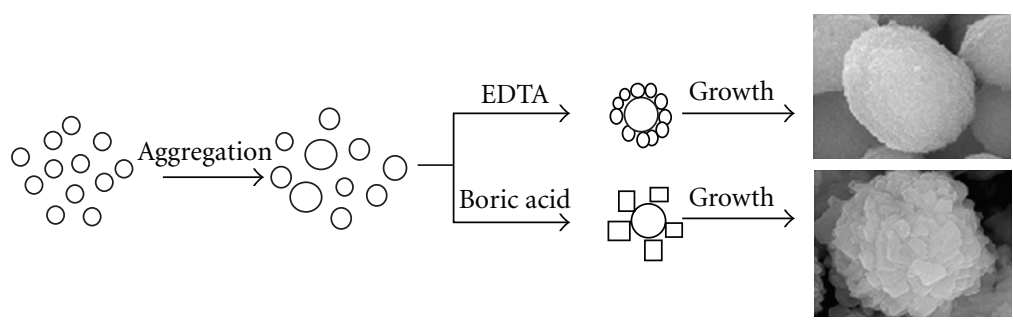

Figure 6: Formation mechanism of $\mathrm{CaCO}_{3}$ with various shapes. 
Stern layer. Thus, the stereochemical arrangement of the carboxylates in conjunction with $\mathrm{Ca}$ binding generates a two-layer subunit cell motif of the vaterite structure, rather than calcite. Subsequent addition of carbonate from solution will be similarly stereochemically directed extending the vaterite motif towards a stable nucleus. In our investigation, the electrostatic and stereochemical interactions of EDTA at the inorganic-organic interface are similar to the above mechanism. The chelation of EDTA with $\mathrm{Ca}^{2+}$ can be seen in Figure 5. The product was a major spherical $\mathrm{CaCO}_{3}$ particle, which was induced by the addition of EDTA. The size of $\mathrm{CaCO}_{3}$ decreased with increasing in the content of EDTA.

The size of $\mathrm{CaCO}_{3}$ particle decreases with increase the amount of EDTA or boric acid, which can form nucleation point, and the larger size of $\mathrm{CaCO}_{3}$ particle was obtained in the acidic conditions. The sphere-like $\mathrm{CaCO}_{3}$ particle is obtained in the additives containing multicarboxyl or multihydroxyl. However, the carboxyl has a stronger induction than hydroxyl, so the surface of $\mathrm{CaCO}_{3}$ was smooth formed in multicarboxyl compound. According the previous research [11], the formation mechanism of $\mathrm{CaCO}_{3}$ with various shapes was shown in Figure 6.

\section{Conclusion}

The sphere-like $\mathrm{CaCO}_{3}$ particles were obtained when the amount of EDTA was more than $1.0 \mathrm{~g}$. The surface of $\mathrm{CaCO}_{3}$ is smooth in the presence of EDTA, and the crystal structure of $\mathrm{CaCO}_{3}$ is major vaterite. However, the sphere-like $\mathrm{CaCO}_{3}$ particle was obtained when the amount of boric acid was less than $1.0 \mathrm{~g}$. The $\mathrm{CaCO}_{3}$ has a rough surface in boric acid solution and a pure calcite structure. The size of $\mathrm{CaCO}_{3}$ particle decreases with increase in the amount of EDTA or boric acid, especially in alkaline condition.

\section{Acknowledgment}

This work is subsidized by the sci-tech innovation foundation of China National Petroleum Corporation (no. 2009D5006-05-04).

\section{References}

[1] A. L. N. Da Silva, M. C. G. Rocha, M. A. R. Moraes, C. A. R. Valente, and F. M. B. Coutinho, "Mechanical and rheological properties of composites based on polyolefin and mineral additives," Polymer Testing, vol. 21, no. 1, pp. 57-60, 2002.

[2] M. C. G. Rocha, A. H. M. F. T. Silva, F. M. B. Coutinho, and A. L. N. Silva, "Study of composites based on polypropylene and calcium carbonate by experimental design," Polymer Testing, vol. 24, no. 8, pp. 1049-1053, 2005.

[3] R. R. Fay, "The goldfish ear codes the axis of acoustic particle motion in three dimensions," Science, vol. 225, no. 4665, pp. 951-954, 1984.

[4] H. Yang, W. Yao, L. Yang et al., "The self-assembly of $\mathrm{CaCO}_{3}$ crystals in the presence of protein," Journal of Crystal Growth, vol. 311, no. 9, pp. 2682-2688, 2009.

[5] E. Altay, T. Shahwan, and M. Tanoğlu, "Morphosynthesis of $\mathrm{CaCO}_{3}$ at different reaction temperatures and the effects of PDDA, CTAB, and EDTA on the particle morphology and polymorph stability," Powder Technology, vol. 178, no. 3, pp. 194-202, 2007.

[6] J. Rudloff and H. Cölfen, "Superstructures of temporarily stabilized nanocrystalline $\mathrm{CaCO}_{3}$ particles: morphological control via water surface tension variation," Langmuir, vol. 20, no. 3, pp. 991-996, 2004.

[7] L. A. Gower and D. A. Tirrell, "Calcium carbonate films and helices grown in solutions of poly(aspartate)," Journal of Crystal Growth, vol. 191, no. 1-2, pp. 153-160, 1998.

[8] C. A. Orme, A. Noy, A. Wierzbicki et al., "Formation of chiral morphologies through selective binding of amino acids to calcite surface steps," Nature, vol. 411, no. 6839, pp. 775-779, 2001.

[9] M. Maas, H. Rehage, H. Nebel, and M. Epple, "A detailed study of closed calcium carbonate films at the liquid-liquid interface," Langmuir, vol. 25, no. 4, pp. 2258-2263, 2009.

[10] A. J. Xie, Y. H. Shen, X. Y. Li et al., "The role of $\mathrm{Mg}^{2+}$ and $\mathrm{Mg}^{2+}$ /amino acid in controlling polymorph and morphology of calcium carbonate crystal," Materials Chemistry and Physics, vol. 101, no. 1, pp. 87-92, 2007.

[11] G. Gao, P. Huang, K. Wang, R. He, and D. Cui, "Gramscale synthesis and shape evolution of micro- $\mathrm{CaCO}_{3}$," Powder Technology, vol. 205, pp. 270-275, 2011.

[12] K. B. Lee, S. B. Park, Y. N. Jang, and S. W. Lee, "Morphological control of $\mathrm{CaCO}_{3}$ films with large area: effect of additives and self-organization under atmospheric conditions," Journal of Colloid and Interface Science, vol. 355, no. 1, pp. 54-60, 2011.

[13] S. Mann, B. R. Heywood, S. Rajam, and J. D. Birchall, "Controlled crystallization of $\mathrm{CaCO}_{3}$ under stearic acid monolayers," Nature, vol. 334, no. 6184, pp. 692-695, 1988. 

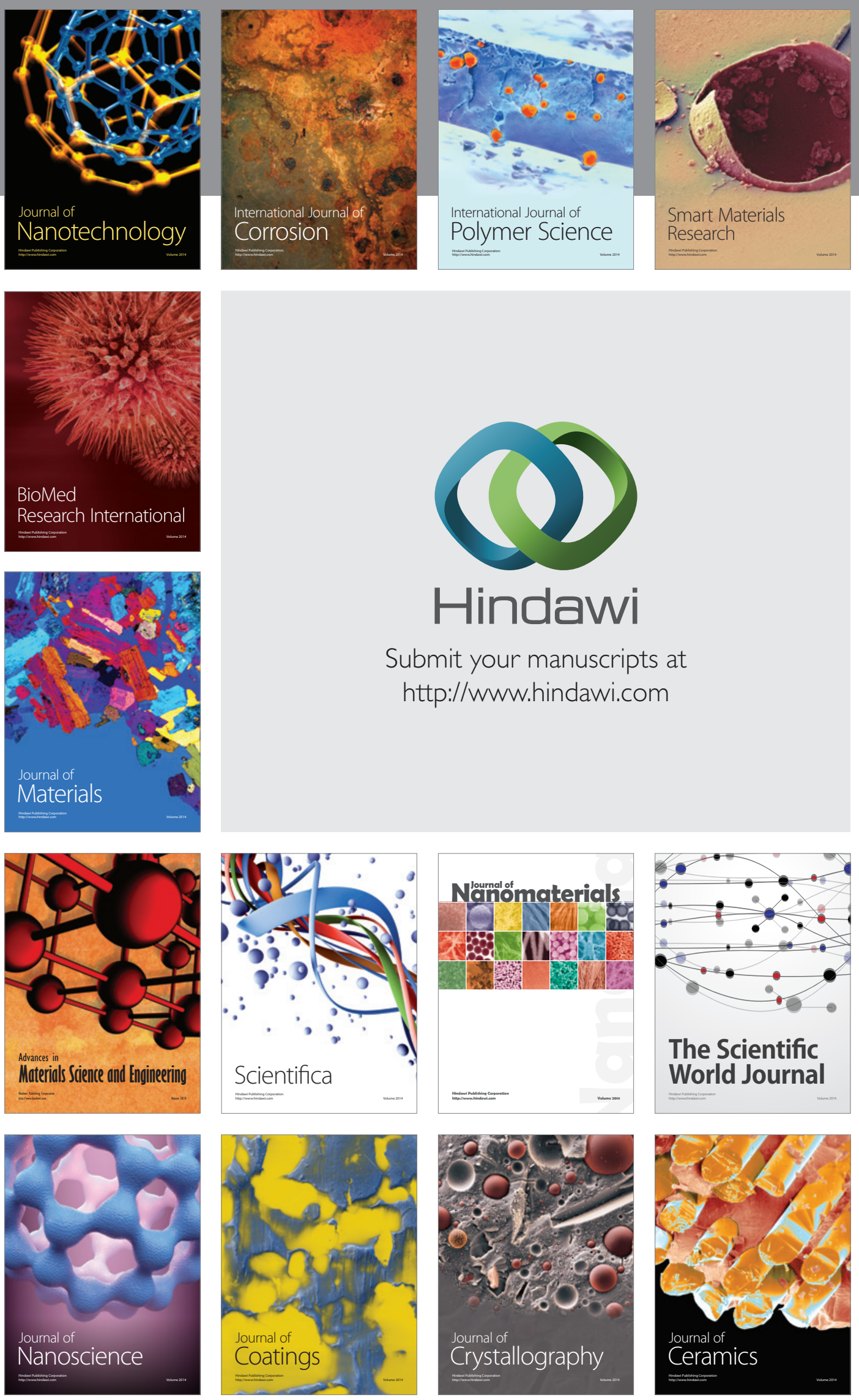

The Scientific World Journal

Submit your manuscripts at

http://www.hindawi.com

\section{World Journal}

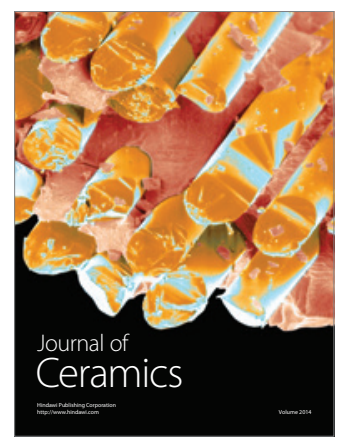

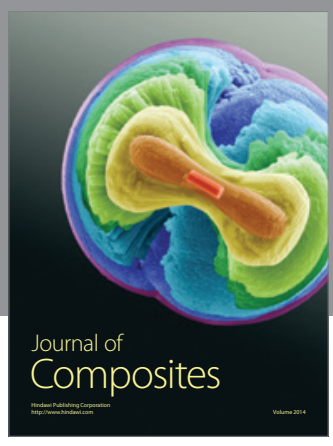
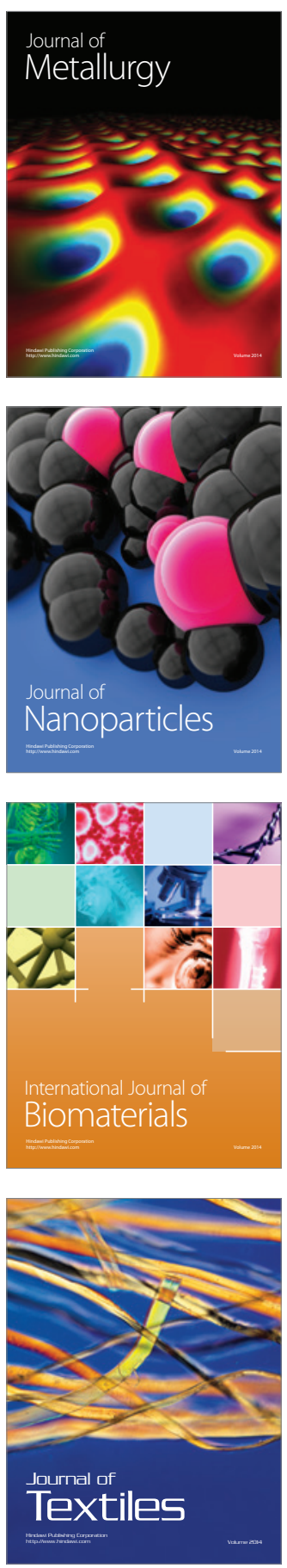